\title{
The place of the relative at the time of the announcement of cancer progression. BABEL, a mixed-method study
}

\section{Isabelle INGRAND}

University Hospital Centre Poitiers: Centre Hospitalier Universitaire de Poitiers

\section{Estelle LAURENT}

University of Poitiers: Universite de Poitiers

\section{Thierry LECOMTE}

University of Tours: Universite de Tours

\section{Oana COJOCARASU}

CH Le Mans: Centre Hospitalier du Mans

\section{Joëlle EGRETEAU}

Centre Hospitalier de Lorient: Centre Hospitalier de Bretagne Sud

\section{Albert ALEBA}

CH Niort: Centre Hospitalier de Niort

\section{José HUREAUX}

Angers Institute of Cancer Research Western France: Institut de Cancerologie de l'Ouest Angers

\section{Philippe COLOMBAT}

University of Tours: Universite de Tours

\section{Emmanuel GYAN}

University of Tours: Universite de Tours

Hugues Bourgeois ( $\nabla$ h.bourgeois@ilcgroupe.fr )

Clinique Victor Hugo https://orcid.org/0000-0001-6682-4916

\section{Research Article}

Keywords: mixed-method research, cancer, progression, patient, relative, communication.

Posted Date: February 1st, 2022

DOI: https://doi.org/10.21203/rs.3.rs-1199631/v1

License: (c) (1) This work is licensed under a Creative Commons Attribution 4.0 International License.

Read Full License 


\section{Abstract \\ Background}

Few studies have evaluated the place of cancer patient's relatives during a consultation bringing bad news.

\section{Aim}

To explore how a relative's presence in these consultations helps communication.

\section{Design}

: Oncologist consultations with patients and relatives for the announcement of cancer progression were recorded, then the different participants completed questionnaires. Answers were further investigated in a few semi-structured interviews. Comparison of quantitative responses (questionnaires) used Wilcoxon's test for matched series. Qualitative analysis (consultations, interviews) used grounded theory. Results were interpreted in a mixed-method integrative approach. This study received the regulatory authorizations.

\section{Setting/participants}

: Patients were aged over 18 , followed for cancer in palliative phase, excluding brain tumors and malignant haemopathies, presented renewed disease progression. Relatives were aged over 18 and authorized by the patient to participate.

\section{Results}

47 documented consultations and 12 interviews (4 triads) were collected. For $93 \%$ of patients, the presence of a relative was considered beneficial. Half the relatives, while remaining discreet, nevertheless contributed to the discussion. Although their relationship to time and their expectations may differ, patients and relatives found the consultation positive. However, oncologists did not check what the dyad had retained. They appeared to underestimate the patient's level of understanding $(P<0.001)$ and perceptions of the seriousness of the disease $(P=0.009)$ but not those of relatives. They did not evaluate the relative's state of health.

\section{Conclusion}


Availability of oncologists to patients and families could be improved. Training via simulation sessions should be adapted to communication implying relative.

\section{Background}

Breaking bad news, "any information which adversely and seriously affects an individual's view of his or her future" is a key moment in the relationship between oncologists and their patients [1]. For oncologists, announcing bad news may be a particularly distressing moment, and numerous negative effects are linked to patient and family reactions [2, 3]. Quality communication contributes to improved satisfaction, treatment adherence, health results, and patient understanding $[4,5]$ making them better able to accept palliative care [6]. The relative will remember how the patient's end-of-life period was managed [7]. From oncologists' viewpoint, family presence is part of "the oncologist's balancing act", especially when communicating on transition to palliative care [3]. Therefore, skillful communication with patients and families is crucial in providing quality end-of-life care, and lack of it is deleterious [8]. Few studies have explored the place of relatives in this communication [9-13].

Alongside, the role of the family varies across cultures $[10,13]$. French medical culture encourages physicians to talk to patients and then to give the family coherent information if the patient agrees [3]. Present recommendations for communicating bad news to cancer patients [14-16] very rarely integrate relatives $[12,17-18]$ and tools available to facilitate communication during physician-patient consultations in cancer care [19] do not always include relatives.

To study the relative's position in consultations bringing bad news, given the complexity of interactions between physicians, patients, and relatives, we adopted a mixed qualitative/quantitative pluri-disciplinary approach [20] (oncology, public health, human and social sciences) combining recordings of consultations, self-administered questionnaires, and semi-directive interviews [21].

\section{Methods}

\section{Population}

Oncologists from 16 administrative areas in western France, representing approximately 9 million inhabitants, recruited patients accompanied by a relative in a consultation, the main aim of which was to announce cancer progression leading to changes in care strategies. Eligible patients were aged over 18, followed for cancer in palliative phase excluding brain tumors and malignant haemopathies, and presented renewed disease progression. The relatives were aged over 18 and authorized by the patient to participate in the study.

\section{Design - Data collection}

Recording of the consultation 
Consultations were recorded after the dyad patient-relative had received verbal and written information on the study aims from the oncologist and had signed informed consent.

\section{Self-administered questionnaires}

Three self-administered questionnaires (patient, relative, oncologist) were designed during ten simulation sessions with volunteering senior physicians and professional actors (playing patients and relatives) then validated by linguists and psychologists [22].

At the end of consultations, oncologists gave patients and relatives questionnaires, to complete independently, collecting information on their socio-demographic characteristics (gender, age, educational level, professional situation) and comprising mirror-items for each version in the form of closed and open questions on their comprehension of the consultation, their expectations, their perceptions of the illness and of the therapeutic decisions. The oncologists also completed questionnaires with the same mirrored themes, enabling comparison of perceptions, and provided their socio-demographic characteristics (gender, age, specialty, qualification) and clinical data on the tumors.

\section{$\underline{\text { Interviews }}$}

Some of the oncologist-patient-relative triads were interviewed by an independent psychologist, using semi-directed interviews to probe the answers to questions on overall feelings, transmission of information, and understanding of the consultation two to three weeks after the consultation. For patient and relative, to facilitate open discussion, these interviews were conducted separately, face-to-face, away from the usual consultation premises.

\section{Data analysis}

Descriptive statistics were used for respondents' demographic and medical characteristics. Means and standard deviations for responses to items on a 10-point Likert scale were calculated. Comparative analysis of patient-relative-oncologist responses was performed using the Wilcoxon test for matched pairs, with two-sided $5 \%$ significance level (SAS 9.4). Consultations and interviews were fully transcribed, preserving participant discourse, and were anonymized. The analysis drew on Grounded Theory [23], an inductive method whereby research themes emerge via systematic coding of recurrences observed in interactions. The potential of a mixed method was used not only in the data collection phase but also in the data analysis phase. Strategies for combining data, such as integration by connecting, merging, or nesting enabled integrative analysis of the results [24].

\section{Results}

\section{Characteristics of the triads}


During 2016, among the 45 oncologists who agreed to take part, 20 included 62 patients (Figure 1). The analysis concerned 47 consultations with complete data (three questionnaires and an audio-recording of the consultation) conducted by 16 physicians aged 33 to 56 (Table 1), and 12 interviews conducted with 4 of the 47 triads (different oncologists and work settings).

Patients were aged 46 to 87 , and $68 \%$ were women. The tumor sites were varied, time since diagnosis ranged from a few months to 17 years. Relatives were aged 25 to 82 , most were spouses (Table 2 , Appendix).

\section{The course of the consultation}

Consultations (Table 3) mainly took place in the oncologists' consulting rooms (94\%), and in most cases $(87 \%)$ the objective was to offer the patient a new line of treatment. Exchanges focused on the announcement of disease progression, therapeutic alternatives, treatment goals, supportive oncological care, or palliative treatment options, with few digressions resulting from a need to change the subject or to reassure a distressed patient.

Oncologists dominated the exchanges (ratio of the number of words to the total number $=63 \%$ [39-87\%]). They began the consultation by questioning the patient on his/her state of health, symptoms (83\%) and/or by explaining examination results (66\%). To announce disease progression, they adopted three methods: preparation of the dyad, slower pace of exchanges, use of euphemisms, or valorization of positive aspects.

"The disease is still around the liver and the lymph node, [...]. The good news is that there is no new damage in the lungs. All the other organs are spared". (Consultation 6)

To describe the situation, oncologists recalled using words like "disease progression", "cancer", "metastases", "tumor", and "nodules", with few references to "discontinuing treatment", "palliative chemotherapy", "palliative care", "life expectancy" or "prognosis". This is confirmed by the recordings. They mentioned prognosis in 6 consultations (13\%), following questions from the patient or relative, generally towards the end of the consultation.

To refer to palliative care, oncologists mentioned measures associated with it: "home hospitalization", "respite hospitalization", "maintaining in the home as long as possible with assistance", and for pauses in treatment they attempted to explain that continuing chemotherapy was not beneficial: "they [the treatments] are not doing you much good", and announced it in the manner of a reasoned decision: "we consider it is not wise to resume treatment".

According to oncologists, both patients and relatives asked for information on disease status ( $79 \%$ and $60 \%$ respectively) and on the treatment plan ( $68 \%$ for patients and relatives alike), i.e. the objective of the consultation, and only a minority broached the issues of a therapeutic alternative (36\% and $34 \%$ respectively) or prognosis (30\% and $19 \%$ respectively). 


\section{The relative}

\section{Their place in the consultation}

Half (49\%) the relatives favored the patient-physician relationship, remaining relatively discreet although contributing to the discussion, but a quarter $(26 \%)$ took over the consultation. One quarter $(23 \%)$ in contrast intervened very little. Relatives generally did not intervene at the start of the consultation. They only spoke when areas where they considered they could contribute were broached, patient quality of life, treatments, and logistics. Husbands were attentive to the quantifiable elements of the disease and wives to the day-to-day management of the illness. Patients' children mainly focused on their parent's comfort.

"While my wife is undressing, there's something that puzzles me [...] in her results, and that is the Gamma GT". (Husband, Consultation 12)

"So, I have adapted his diet, with more protein... I try to find the right foods". (Wife, Consultation 43)

"That [loss of appetite] was the reason for our visit to her [the mother]. To try and give her new tastes, something different". (Son, Consultation 9)

To contribute to the consultation certain relatives called on resources derived from their professional activity (medical, relational, or linguistic skills) and they mostly approached the illness from a relatively outside (non-somatic and non-professional) point of view or based on their own experience.

"He [the patient] says to me "I'd like to see you [in my position]". But I've already been there, when I was in a car accident with my parents, I had broken bones all over and I stayed one/three months in bed!" (Wife, Consultation 46)

The patient-oncologist dyad was dominant, but according to oncologists, in $62 \%$ of the triadic consultations, both verbal and non-verbal interactions contributed to the way the consultation unfolded.

\section{Apresence that is beneficial}

According to $93 \%$ of patients, the presence of a relative helped in the consultation, (85\% positive comments in questionnaires). Relatives were able to detail, correct or add elements related to the patient's health, and help patients understand the results.

"He helped me ask questions it would not have occurred to me to ask, and his being there reassured me". (Patient, Questionnaire 32)

"It's more than essential for the two of us to be there, to hear everything, and to understand, because sometimes when you get home you find you haven't heard the same thing". (Wife, Interview 4)

For oncologists, the presence of most relatives was also seen as beneficial, making the announcement easier, avoiding misunderstandings, or enabling better understanding of the illness. One oncologist 
confirmed that it was more "comfortable" to announce bad news to a patient accompanied by a relative.

"There's nothing worse than announcing [bad news] to a person on their own. You won't use the same words, you won't have the resource person alongside who will provide support after the consultation, so it does change the content of the interview a little, and the way it is conducted". (Interview 11)

During the consultations, relatives were allies for patient and oncologist - the oncologist relying on the relative in cases of non-compliance, refusal of treatment, or misunderstanding by the patient, and the patient relying on the relative to back up his/her therapeutic choice. Thus, care management could be influenced by interactions within the triad.

"Patient: We talked about it. I don't know if you remember, about tablets, but I don't know if... maybe at least try it? [short silence]. Try it. But I don't know. It's your decision, isn't it?

Wife: Maybe it would not be as strong as the normal chemo, I don't know [...] Maybe it could temper things a bit, chemo-tablets....". (Consultation 1)

The relatives attending the consultation had acquired better knowledge of the disease and favored information-sharing in the family, acting as an interface with other family caregivers.

"Oncologist: Would you like me to draw another diagram?

Wife: Yes, so that I can get things clear for my son - for our children. It was he who wanted it mostly". (Consultation 28)

"I don't want to miss consultations because I like to have the doctor's opinion". (Wife, Interview 16)

But a source of complexity.

While certain patients wished to be informed in direct manner ("she didn't beat about the bush", "since pretenses are not really the order of the day"), others were not ready ("I would have other questions to ask, but I'm not ready yet to hear the answers"). Thus, certain relatives exposed the patient to questions they did not wish to broach.

"To deliver information our first job is to listen, you need to listen to the person, and then to understand what the person really wants to hear, in fact it's the patient who guides us". (Oncologist, Interview 4)

The relationship with time is not the same for patients and relatives since expectations can differ. Patients envisaged the short term "How many chemo sessions?". The same applies to physicians "I'll see you again in two weeks", "Let's move forward step by step, if you agree". Relatives have questions on the more distant future: apprehensions about what will happen, life expectancy, how to prepare for the future.

In these triadic consultations, oncologists also expressed the desire to examine patients privately, preserving their intimacy, in a suitable setting. Symptoms perceived as intimate or private appeared 
difficult to express for some patients in the presence of a relative. For relatives, prognosis was a difficult subject to broach in presence of the patient.

"I had a spell when I was having colored stools - not red, or brown, but... well it was... but now it's really brown, and - well - quite a lot.... Anyway... is it losing blood that could have contributed to me feeling weaker?" (Patient after her son went out, Consultation 9)

Of the 47 consultations, only two, on the initiative of the relative, broached the subject of his/her physical and mental health.

"In fact, when you accompany a patient, what I find difficult for the helper is that people always ask about the patient. If I had been able to see the psychologist, it would have been a time just for me". (Wife, interview 11)

\section{Representations and perceptions of the triad - outcome of the consultation}

During the consultations, oncologists maintained a balance, broaching the subject of palliative care while preserving hope, all within a short time-lapse. Both patients and relatives retained words that characterized the illness ("aggravation", "cancer", "progression"), but also words of hope ("not serious", "confident", "hope").

According to oncologists, they provided complete information in only 17 consultations (36\%) and thought they would need to return to the subject in later consultations. Although they broached the subject of prognosis very little, they (rightly) considered that in 41 consultations (79\%), both patient and relative had understood that the disease was incurable.

"The disease has progressed, and the treatment has had to be altered and adapted, because the cancer has attacked the lumbar vertebrae - it's distressing", "We both know that the disease has developed a lot and that the drugs are there just to slow it temporarily". (Patient and relative, Questionnaire 41)

One patient even added: "Because at one stage I could see in your face that I wasn't going to get over this. I was very upset, doctor. Very upset." (Patient, Consultation 34)

Perceptions of the consultation (Table 4) were approached through the triads' responses to questionnaires. While patients and relatives had apprehensions of the seriousness of the disease that differed little $(P=0.56)$, oncologists underestimated the perceptions that patients had of the seriousness of their disease $(P=0.0090)$, but not those of the relatives $(P=0.47)$. They also underestimated patients' understanding of the words they used $(P=0.0005)$, but not the relatives' understanding $(P=0.63)$. Alongside, the oncologist questioned the relative on what he/she thought of the patient's situation in only one consultation, and more patients than relatives $(52 \% v s 39 \%)$ had no difficulty in understanding the oncologists' words. 
Following the consultation (Table 5), relatives seemed to underestimate patients' ability to deal with the explanations by the oncologist, considering patients less serene than they said they were $(P<0.0001)$. However, all felt trustful after these explanations $(P=0.14)$.

Around twice as many relatives as patients ( $26 \%$ vs $16 \%$ ) would have liked more information, on disease progression, prognosis, and treatments, and 7 relatives (15\%) said they had not been able to ask all the questions they wished during the consultation because the patient was present. Certain relatives $(11 \%)$ considered that it was not desirable to give the patient full information.

Nevertheless, both patients and relatives appreciated being supported in their plans and welcomed treatment postponement if it did not interfere with disease progression.

Finally, patients and relatives considered that oncologists listened to the dyad. However, it can be noted that at the end of the consultation no oncologist checked the understanding by the patient or the relative of the consultation by asking them to reword what had been said.

\section{Discussion}

This mixed-method study echoes a recent systematic review that concluded that further research was needed to understand communication with relatives of patients approaching the end-of-life in different settings [25]. It showed that the presence of an accompanying person (here a relative) in a consultation can be beneficial, but that it can also complicate the announcement of disease progression, showing the need to improve tools facilitating communication among protagonists.

The degree of empathy felt by patients and their relatives, and the experience of the consultation were overall very positive. Although none of the oncologists checked what patient and relative had retained from the consultation, they appeared to underestimate the patient's level of understanding and perception of the seriousness of the disease but not those of relatives. The possible hypotheses are, for oncologists, the impact of the emotional load in the consultations, and the distress generated by what they had to say [26-28]. Thus, these supposedly greater difficulties in understanding for the patient than for the relative could be linked to the oncologist's secret hope that the patient has not understood everything in the announcement. They provided information, seeking to protect the patient more than the relative, also protecting themselves from possible guilt at having said too much to the patient, or because the patient has understood too well. It is also possible that, because certain words are impossible to utter, the oncologist's non-verbal communication was more important for the relative than for the patient, possibly at moments before or after the clinical examination.

During the consultation, oncologists tried to include relatives, who were implicated in different ways, since only half of them contributed to the consultation without monopolizing it. Very few of them broached the physical and psychological health of relatives by asking them directly about their own situation. Yet while accompaniers provide support, they also need support [29-11]. The relative is not just a partner, but also a "second patient in distress" [30]. 
For the patient, symptoms perceived as private or intimate, and for the relative, prognosis, were more difficult subjects to address in triadic consultation. Relatives did not ask all the questions they would have liked to ask and would have liked more information. Their demand for information was high, higher than that of the patients, and some appeared to wish to restrict the patient's access to full information. The study confirmed that, in this context of treatment discontinuation and orientation towards palliative care, while patients were in a logic of seeking honest information [12], they were sometimes unwillingly confronted with questions they were reluctant to raise $[31,11]$. Patients and relatives did not always move at the same pace, did not have the same information need [32]. Oncologists should identify the needs and expectations of patients, but also those of relatives, to detect discrepancies within the dyad and avoid forcing the pace of information delivery. They should adapt to changing alliances, ensure that dialogue is maintained within the dyad and monitor interactions.

The relative provides support for the patient but is also a resource for the physician in helping to maintain compliance with treatment and providing emotional support. Oncologists can feel relieved of the need to provide particularly close emotional support, since it is provided by the relative [33]. For the oncologist, this enables identical information to be given to both members of the dyad, and provides complementary information on the patient, since the relative is familiar with the patient's life. Thus, the presence of the relative is often beneficial [11]. However, certain dyadic alliances can weaken the authority of the oncologist [34] or make exchanges more difficult, such as when relatives take the patient's side to demand inappropriate treatments or monopolize the conversation [11, 35-37]. Furthermore, some relatives appeared to underestimate the patient's ability to cope with the oncologist's explanations, contaminated by their own perceptions of the situation. Oncologists should consider these different contexts.

This study shows that each consultation is unique, depending on the manners of being and doing of each participant, but this does not exclude a common typology. To announce disease progression, oncologists relied on preparing the ground [3], slowing their discourse [38], emphasizing positive aspects and remaining in a dynamic of action $[39,6]$. Patients and relatives entered the consultation with different objectives, patients to discuss the present situation, and relatives to identify the best treatment solution [13]. Relatives generally let the patient-physician dialogue unfold around the symptoms and the illness, and only spoke when treatments were broached. With the changes in socio-cultural representations, taboos concern metastatic tumors more than the cancer itself [40]. For the oncologists, the difficulty was more how to position themselves towards prognosis [41], or palliative care, although it is particularly relevant to improve patient quality-of-life and reduce medical costs [42]. They tended to prefer associated themes and an earlier study showed that while the words "palliative", "supportive" and "hospice" are commonly used interchangeably, they have differing impact [43]. The exchanges between oncologists and dyads confirmed that the word of the physician often dominated the exchanges.

There is thus a need to determine how oncologists can support relatives [44] and integrate them into the consultation to foster the therapeutic alliance. 
The method used is original, and the number of triads included (47 and 20 physicians) is larger than in earlier studies $[9,13]$. However, one limitation is the difference between the potential study population and the oncologists who took part and may also have selected patients. Lack of time in consultations was the main reason given for non-participation.

\section{Conclusion And Perspectives}

This study highlights possible improvements in triadic oncology consultations:

i. optimizing the consultation premises layout to ensure patient privacy,

ii. taking time to determine what patients and relatives know and/or understand about the situation, what they expect from the consultation, and what they are feeling,

iii. taking an interest in patients' plans,

iv. taking an interest in the accompanier, assessing his/her state of health and preoccupations,

v. improving announcements of disease progression to broach considerations of timing, supportive care, incurability, and palliative care,

vi. managing the consultation in more interactive mode, availability to respond to questions and asking participants to reword what has been said.

Thus, the need is to raise awareness among physicians and students of the challenges of this situation. Training via simulation sessions has already shown promising results in improving communication between doctor and patient [22] and should be adapted to communication implying relative. Further evaluation should validate the transfer of theoretical knowledge to clinical practice. Each country should develop its own guidelines adapted to social and cultural contexts.

\section{Declarations}

Funding. This study was supported by the "Cancéropole Grand-Ouest" and funded by "Les régions Pays de Loire, Poitou-Charentes, Centre et Bretagne". BABEL was selected by the "conseil scientifique du CGO" on 12/9/2013 and the 4 Regions voted the budget for the project on 3/10/2013.

Conflicts of interest / Competing interests : The authors have no potential conflicts of interest to report with respect to the research, authorship, and/or publication of this article.

Availabilty of data and materiel : In application of European and French regulations, research data could not be released.

Code availability : NA 
Authors' contributions: HB conceived the study. HB, II, JH, PC designed the research and wrote the research protocol. II and HB defined the concept and scope of the article. II wrote the first draft. HB provided expert knowledge on the data. II, EL performed the analyses. All authors commented on and contributed to the final version of the text.

Ethics approval : This study was approved by the CCTIRS (Comité Consultatif pour le Traitement de I'Information en matière de Recherche dans le domaine de la Santé) on November 26, 2014 (file n¹4 744), and received regulatory authorization of the CNIL (Commission Nationale de I'Informatique et des Libertés) on November 9, 2015 (file DR-2015-362). Ethical approval was given by the Espace de Réflexion Ethique de la Région Centre (ERERC), on March 4, 2015 (project n² 2015-008).

Consent to participate : Informed consent was obtained from all individual participants included in the study (tape recorder \& questionnaires)

Consent for publication : Informed consent was obtained from all individual participants included in the study (verbatim)

Acknowledgements. The authors would like to thank

Dr C Perrin (CEM Rennes), J Eudeline (CEM Rennes), A Mercier-Blas (Clinique Saint Grégoire, Rennes), J Egreteau (CH Lorient), T Lecomte (CHU Tours), MA By (CHU Tours), PE Cailleux (Centre d'oncologie et de radiotherapie 37 Chambray Les Tours), T Boisserie (Centre d'oncologie et de radiotherapie 37 Chambray Les Tours), $\mathrm{O}$ Arsène (CH Blois), D Tougeron (CHU Poitiers), F Minne (CHU Poitiers), A Aléba (CH Niort), OZ Cojocarasu (CH Le Mans), O Molinier (CH Le Mans), C Fonsegrive (CH Le Mans), F Denis (clinique V Hugo Le Mans), Y Pointreau (clinique V Hugo Le Mans), J Dômont (clinique V Hugo Le Mans), N Bénéton (CH Le Mans) for their participation in the study.

Sarah Dujoncquoy for her help in designing the protocol study, Nicolas Palierne for his help in facilitating the collection of questionnaires during the study period, Camille Pousse for the interviews, Karine Dupont for her help for the retranscription of consultations, and Pierre Ingrand for helpful insights in the statistical analyses and manuscript revision.

Angela Verdier for French to English the translation.

\section{References}

1. Buckman R (1992) Breaking Bad news: A guide for health care professionals. Baltimore. Johns Hopkins University Press.

2. Desauw A, Christophe V, Antoine P, Cattan S, Nandrino JL (2009) Quelle perception les praticiens ontils de l'annonce de mauvaises nouvelles en oncologie? Analyse qualitative du vécu et des stratégies de régulation émotionnelle. Psycho-Oncologie 3(3):134-139. https://doi: 10.1007/s11839-009-0143-z 
3. Bousquet G, Orri M, Winterman S, Brugière C, Verneuil L, Revah-Levy A (2015) Breaking Bad News in Oncology: A Metasynthesis. J Clin Oncol 33(22):2437-2443. https://doi: 10.1200/JC0.2014.59.6759.

4. Ong LM, Visser MR, Lammes FB, de Haes JC (2000) Doctor-patient communication and cancer patients' quality of life and satisfaction. Patient Educ Couns 41(2):145-156. https://doi: 10.1016/s0738-3991(99)00108-1.

5. Zachariae R., Pedersen CG, Jensen AB, Ehrnrooth E, Rossen PB, von der Maase H (2003) Association of perceived physician communication style with patient satisfaction, distress, cancer-related selfefficacy, and perceived control over the disease. Br J Cancer 88(5):658-665. https://doi: 10.1038/sj.bjc.6600798.

6. National Cancer Institute (NCl) Bethesda, MD: National Cancer Institute (2014). NCl: PDQ Communication in Cancer Care.

[http://www.cancer.gov/cancertopics/pdq/supportivecare/communication/patient] Accessed $16 / 09 / 2021$

7. Boyle DA. Nursing Care at the End of Life: Optimizing Care of the Family in the Hospital Setting. Clin J Oncol Nurs 23(1):13-17. https://doi: 10.1188/19.CJON.13-17.

8. Seccareccia D, Wentlandt K, Kevork N, Workentin K, Blacker S, Gagliese L, Grossman D, Zimmermann C (2015) Communication and Quality of Care on Palliative Care Units: A Qualitative Study. J Palliat Med 18(9):758-764. https://doi: 10.1089/jpm.2014.0408.

9. Korfage IJ, Audrey S, Hak T, Blazeby JM, Abel J, Campbell R (2013) Recognising the importance of 'family timeout' in consultations: an exploratory qualitative study. BMJ Open 3(1):e002144. https://doi: 10.1136/bmjopen-2012-002144.

10. Zamanzadeh V, Rahmani A, Valizadeh L, Ferguson C, Hassankhani H, Nikanfar, AR, Howard F (2013) The taboo of cancer: The experiences of cancer disclosure by Iranian patients, their family members and physicians. Psychooncology 22:396-402. https://doi: 10.1002/pon.2103

11. Laidsaar-Powell R, Butow P, Bu S, Fisher A, Juraskova I (2016) Attitudes and experiences of family involvement in cancer consultations: a qualitative exploration of patient and family member perspectives. Support Care Cancer 24(10):4131-4140. https://doi: 10.1007/s00520-016-3237-8.

12. Datta SS, Tripathi L, Varghese R, Logan J, Gessler S, Chatterjee S, Bhaumik J, Menon U (2017) Pivotal role of families in doctor-patient communication in oncology: a qualitative study of patients, their relatives and cancer clinicians. Eur J Cancer Care (Engl) 26(5). https://doi: 10.1111/ecc.12543.

13. Lee GL, Teo I, Kanesvaran R (2018) The Complexities of Doctor-Patient-Family Communication in an Asian Oncology Setting: Concordance and Discordance Among Patient Preferences, Family Preferences, and Perceived and Actual Communication. Health Commun 33(2):95-101. https://doi: 10.1080/10410236.2016.1239303.

14. Baile WF, Buckman R, Lenzi R, Glober G, Beale EA, Kudelka AP (2000) SPIKES-A six-step protocol for delivering bad news: Application to the patient with cancer. Oncologist 5(4):302-311. https://doi: 10.1634/theoncologist.5-4-302. 
15. Gilligan T, Coyle N, Frankel RM, Berry DL, Bohlke K, Epstein RM, Finlay E, Jackson VA, Lathan CS, Loprinzi CL, Nguyen LH, Seigel C, Baile WF (2017) Patient-Clinician Communication: American Society of Clinical Oncology Consensus Guideline. J Clin Oncol 35(31):3618-3632. https://doi: 10.1200/JCO.2017.75.2311.

16. Gilligan T, Bohlke K, Baile WF (2018) Patient-Clinician Communication: American Society of Clinical Oncology Consensus Guideline Summary. J Oncol Pract 14(1):42-46. https://doi: 10.1200/JOP.2017.027144.

17. Parikh PP, White MT, Buckingham L, Tchorz KM (2017) Evaluation of palliative care training and skills retention by medical students. J Surg Res 2017, 211:172-177. https://doi: 10.1016/j.jss.2016.11.006.

18. Tattersall MHN (2018) Patient-Oncologist Communication: Sharing Decisions in Cancer Care. J Oncol Pract 14(1):9-10. https://doi: 10.1200/JOP.2017.028068.

19. Licqurish SM, Cook OY, Pattuwage LP, Saunders C, Jefford M, Koczwara B, Johnson CE, Emery JD (2019) Tools to facilitate communication during physician-patient consultations in cancer care: An overview of systematic reviews. CA Cancer J Clin 69(6):497-520. https://doi: 10.3322/caac.21573.

20. Fàbregues S, Hong QN, Escalante-Barrios EL, Guetterman TC, Meneses J, Fetters MD (2020) A Methodological Review of Mixed Methods Research in Palliative and End-of-Life Care (2014-2019). Int J Environ Res Public Health 17(11):3853. https://doi: 10.3390/ijerph17113853.

21. Lim CT, Tadmor A, Fujisawa D, MacDonald JJ, Gallagher ER, Eusebio J, Jackson VA, Temel JS, Greer JA, Hagan T, Park ER (2017) Qualitative Research in Palliative Care: Applications to Clinical Trials Work. J Palliat Med 20(8):857-861. https://doi: 10.1089/jpm.2017.0061.

22. Hureaux J, Cartier-Chatron I, Bourgeois H, Rolland-Lozachmer G, Ingrand I, Colombat P, Urban T (2016) Use of Simulation to Validate Questionnaires on a Sensitive Subject. Simul Healthc 11(1):656. https://doi: 10.1097/SIH.0000000000000145.

23. Glaser BG, Strauss AL (2010) La découverte de la théorie ancrée. Stratégies pour la recherche qualitative. Armand Colin, coll. "Individu et Société "

24. Creswell JW, Plano Clark VL (20100) Designing and Conducting Mixed Methods Research. Sage

25. Anderson RJ, Bloch S, Armstrong M, Stone PC, Low JT (2019) Communication between healthcare professionals and relatives of patients approaching the end-of-life: A systematic review of qualitative evidence. Palliat Med 33(8):926-941. https://doi: 10.1177/0269216319852007.

26. Granek L, Krzyzanowska MK, Nakash O, Cohen M, Ariad S, Barbera L, Levy R, Ben-David M (2016) Gender differences in the effect of grief reactions and burnout on emotional distress among clinical oncologists. Cancer 122(23):3705-3714. https://doi: 10.1002/cncr.30236.

27. Granek L, Barbera L, Nakash O, Cohen M, Krzyzanowska MK (2017) Experiences of Canadian oncologists with difficult patient deaths and coping strategies used. Curr Oncol 24(4):e277-e284. https://doi: 10.3747/co.24.3527.

28. Paiva CE, Martins BP, Paiva BSR (2018) Doctor, are you healthy? A cross-sectional investigation of oncologist burnout, depression, and anxiety and an investigation of their associated factors. BMC 
Cancer 18(1):1044. https://doi: 10.1186/s12885-018-4964-7.

29. Ream E, Pedersen VH, Oakley C, Richardson A, Taylor C, Verity R (2013) Informal careers' experiences and needs when supporting patients through chemotherapy: a mixed method study. Eur J Cancer Care (Engl) 22(6):797-806. https://doi: 10.1111/ecc.12083.

30. Bréchot JM (20017) Quelle vérité au patient et à sa famille ? Rev Mal Resp 24(8 Pt2):6S131-136.

31. Furber L, Bonas S, Murtagh G, Thomas A (2015) Patients' experiences of an initial consultation in oncology: knowing and not knowing. Br J Health Psychol 20(2):261-73. https://doi: 10.1111/bjhp.12096.

32. Saltel P, Gauvain-Piquard A, Landry-Dattee N (2001) L'information de la famille d'un patient adulte atteint de cancer. Bull Cancer 88(4):399-405.

33. Burkhalter JE, Bromberg SR (2003) Family-Oncologist Communication in Cancer Patient Care. Cancer Invest 21(6):915-923. https://doi: 10.1081/cnv-120025094.

34. Castel $P$ (2005) Le médecin, son patient et ses pairs. Une nouvelle approche de la relation thérapeutique. Revue française de sociologie 46(3):443-467. https://www.jstor.org/stable/25046550

35. Beisecker AE, Moore WP (1994) Oncologists' Perceptions of the Effects of Cancer Patients' Companions on Physician-Patient Interactions. J Psychosoc Oncol 12(1-2):23-39.

36. Saint-Marc D (2012) L'autonomie des malades face à leur prise en charge et à la profession médicale : le cas des maladies atteints de cancer. Sociologie Santé 36(10):253-268. http://bdspehesp.inist.fr/vibad/index.php?action=getRecordDetail\&idt=467870

37. Rosenberg LB, Greenwald J, Caponi B, Doshi A, Epstein H, Frank J, Lindenberger E, Marzano N, Mills LM, Razzak R, Risser J, Anderson WG (2017) Confidence with and Barriers to Serious IIIness Communication: A National Survey of Hospitalists. J Palliat Med 20(9):1013-1019. https://doi: 10.1089/jpm.2016.0515.

38. McHenry M, Parker PA, Baile WF, Lenzi R (2012) Voice analysis during bad news discussion in oncology: reduced pitch, decreased speaking rate, and nonverbal communication of empathy. Support Care Cancer 20(5):1073-1078. https:// doi: 10.1007/s00520-011-1187-8.

39. Ménoret M (2007) Informer mais convaincre : incertitude médicale et rhétorique statistique en cancérologie. Sciences sociales et santé 25(1):33-54. https://doi: 10.3406/sosan.2007.1701

40. Fainzang S (2013) Champ-contrechamp : La relation médecin-malade entre anciennes et nouvelles normes. Anthropologie et Sociétés 37(3):83-97. https://doi.org/10.7202/1024080ar

41. Singh S, Cortez D, Maynard D, Cleary JF, DuBenske L, Campbell TC (2017) Characterizing the Nature of Scan Results Discussions: Insights Into Why Patients Misunderstand Their Prognosis. J Oncol Pract 13(3):e231-e239. https://doi: 10.1200/JOP.2016.014621.

42. Epstein RM, Street RL (2007) Patient-Centered Communication in Cancer Care: Promoting Healing and Reducing Suffering. Publication No. 07-6225. Bethesda, MD: National Institutes of Health, 2007.

43. Fishman JM, Greenberg P, Bagga MB, Casarett D, Propert K (2018) Increasing Information Dissemination in Cancer Communication: Effects of Using "Palliative," "Supportive," or "Hospice" Care 
Terminology. J Palliat Med 21(6):820-824. https://doi: 10.1089/jpm.2017.0650.

44. Schulz R, Beach SR, Friedman EM, Martsolf GR, Rodakowski J, James AE 3rd (2018) Changing Structures and Processes to Support Family Caregivers of Seriously III Patients. J Palliat Med 2018 21(S2):S36-S42. https://doi: 10.1089/jpm.2017.0437.

45. Smith MB, Macieira TGR, Bumbach MD, Garbutt SJ, Citty SW, Stephen A, Ansell M, Glover TL, Keenan G (2018) The Use of Simulation to Teach Nursing Students and Clinicians Palliative Care and End-ofLife Communication: A Systematic Review. Am J Hosp Palliat Care 35(8):1140-1154. https://doi: $10.1177 / 1049909118761386$.

\section{Tables}

Table 1: Characteristics of investigators $(n=16)$

\begin{tabular}{|ll|}
\hline Age (years) $(\mathrm{n}=13)$ & $42.1(7.2)$ \\
Mean (sd) & {$[33-56]$} \\
\hline min-max] & $n(\%)$ \\
\hline Gender & $4(25 \%)$ \\
\hline F & $12(75 \%)$ \\
\hline M & \\
\hline Specialty & $10(62 \%)$ \\
\hline Medical Oncologist & $3(19 \%)$ \\
\hline Radiation Oncologist & $3(19 \%)$ \\
\hline Organ Specialists & \\
\hline Qualification & $3(19 \%)$ \\
\hline university degree in palliative care & $2(12 \%)$ \\
\hline university degree in pain management & $2(12 \%)$ \\
\hline university degree in oncogeriatrics & $13(81 \%)$ \\
\hline Trained in communication & $2(12 \%)$ \\
\hline Working place & $3(19 \%)$ \\
\hline University hospital & $6(44 \%)$ \\
\hline General hospital & $5(25 \%)$ \\
\hline Private hospital & \\
\hline Cancer center & \\
\hline
\end{tabular}

Page 16/27 
Table 2: Characteristics of patients and relatives $(n=47)$ 


\begin{tabular}{|c|c|c|}
\hline & Patient & Relative \\
\hline Age & & $62.8(12.7)[25-82]$ \\
\hline mean (sd) [min-max] & $69.1(8.6)[46-87]$ & \\
\hline Relationship of the family member to the patier & & $\mathrm{n}(\%)$ \\
\hline Spouse & & $38(81 \%)$ \\
\hline Child & & $8(17 \%)$ \\
\hline Grandchild & & $1(2 \%)$ \\
\hline Gender & $\mathrm{n}(\%)$ & $\mathrm{n}(\%)$ \\
\hline $\mathrm{F}$ & $28(60 \%)$ & $23(49 \%)$ \\
\hline M & $19(40 \%)$ & $24(51 \%)$ \\
\hline Employment status & $\mathrm{n}(\%)$ & $\mathrm{n}(\%)$ \\
\hline In operation & $8(17 \%)$ & $11(23 \%)$ \\
\hline Retired & $38(81 \%)$ & $35(75 \%)$ \\
\hline Not working (stay-at-home mother, disability) & $1(2 \%)$ & $1(2 \%)$ \\
\hline Highest degree & $\mathrm{n}(\%)$ & $\mathrm{n}(\%)$ \\
\hline Below the baccalaureate & $34(77 \%)$ & $31(66 \%)$ \\
\hline Greater than or equal to the baccalaureate & $10(23 \%)$ & $16(34 \%)$ \\
\hline Cancer typology & $\mathrm{n}(\%)$ & \\
\hline Digestive (colon/esophagus/rectum) & $16(34 \%)$ & \\
\hline Breast & $12(26 \%)$ & \\
\hline Gynecological cancers & $6(13 \%)$ & \\
\hline Pancreas & $5(11 \%)$ & \\
\hline ENT & $2(4 \%)$ & \\
\hline Lungs & $2(4 \%)$ & \\
\hline Kidney & $3(6 \%)$ & \\
\hline Biliary Tract & $1(2 \%)$ & \\
\hline \multicolumn{3}{|l|}{ Age of diagnosis (years) $(n=41)$} \\
\hline mean (sd) [min-max] & $4.0(3.8)[0-17]$ & \\
\hline WHO Stage & $\mathrm{n}(\%)$ & \\
\hline
\end{tabular}




\begin{tabular}{|ll|}
0 & $13(28 \%)$ \\
2 & $20(43 \%)$ \\
$3-4$ & $10(21 \%)$ \\
\hline EVA pain $(\mathrm{n}=43) / 10$ & $4(9 \%)$ \\
mean (sd) [min-max] & $1.93(2.05)[0-8]$ \\
\hline Disease prognosis & $\mathrm{n}(\%)$ \\
\hline A few weeks & $2(4 \%)$ \\
\hline From a few weeks to a few months & $8(17 \%)$ \\
\hline A few months or more & $37(79 \%)$ \\
\hline
\end{tabular}

Table 3: Characteristics of the consultation $(n=47)$ 
The position adopted by the oncologist towards the patient and the accompanying person

Sitting at the desk facing the patient and accompanier

Sitting at the desk beside the patient and the accompanier

Standing in the patient's room with the accompanier alongside

Sitting in the patient's room with the accompanier alongside

The information and proposals that the physician wished to deliver to patient and accompanier Initiation of a new line of treatment / Participation in a clinical trial

Discontinuation of specific treatments, initiation of supportive or palliative care and/or orientation to long-term facility without new line of treatment

Pause in specific treatments

The physician started the consultation

with the patient (How are you feeling? question(s) on symptoms...)

with the disease (scan, blood counts...)

In another manner

Words the physicians thought they used in the consultation

Progression

Cancer

Metastases

Aggravation

Tumour

Nodule

Symptoms

Cancer cells

Quality of life 
No cure

Relapse

Risk-benefit ratio

Supportive care

Comfort

Therapeutic pause

Accompaniment

Discontinuation of treatment

Palliative chemotherapy

Making the most of it

Prognosis

Life expectancy

Palliative care

Remission

Death

The unfolding of the consultation led the physician to provide information that was

Complete

Partial

Minimal

The physician considers he will need to return to the information in a later consultation

* information on a new chemotherapy protocol to be instated; a few words on the recording; recall of the previous treatment 
Table 4: Cross-representation of patient, relative and oncologist $(n=47)$ 
Current severity of the disease

$(0=$ mild $-10=$ severe $)$ as estimated by the patient

as estimated by the relative

Perception gap at

scales $\Delta$

mean (sd)

min-max]

8.09 (1.76) [5-10]

$(n=45)$ mean (sd)

min-max]

7.84 (1.78) [4-10]

$(n=45)$
Mean (sd)

$P$

$\Delta=0.18$

(1.67)

0.56

Perception of the current severity of the disease

$(0=$ mild $-10=$ severe as estimated by the patient according to the oncologist

7.23 (1.31) [4-10]

$(n=47)$

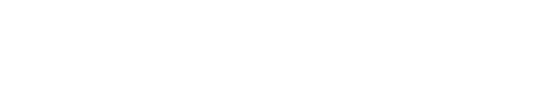

as estimated by the relative according to the oncologist

$7.76(1.32)[4-10]$

$(n=45)$

$\Delta=0.47$

$\Delta=0.16(1.90)$

Perception gap at

scales $\Delta$

Mean (sd)

$\begin{array}{lll}P & 0.0090 & 0.47\end{array}$

Difficulty understanding as estimated by the patient the oncologist's words

$(0=$ no difficulties -

$10=$ many difficulties) as estimated by the relative

Perception gap at scales $\Delta$

Mean (sd)

1.36 (2.04) [0-8] median 0 $(n=45)$
1.89 (2.49) [0-9] median 1

$(n=46)$
$P$

$\triangle=-0.70$

(3.05)

0.11

Level of understanding

$(0=$ make sense of everything $-10=$ be meaningless) patient's level of understanding estimated by the oncologist 2.62 (1.41) [0-7], median 2 relative's level of understanding estimated by the oncologist

1.93 (1.20) [0-5], median 2 


$$
(n=47) \quad(n=46)
$$

Perception gap at

scales $\Delta$

Mean (sd)

$$
\begin{array}{ll}
\Delta=-1.27(2.52) & \Delta=-0.022(2.19) \\
0.0005 & 0.63
\end{array}
$$

Table 5: The outcome of the consultation $(n=47)$ 


\begin{tabular}{|c|c|c|c|}
\hline & $\begin{array}{l}\text { According to the } \\
\text { patient }\end{array}$ & $\begin{array}{l}\text { According to the } \\
\text { relative }\end{array}$ & $P$ \\
\hline & $\begin{array}{l}\operatorname{mean}(\mathrm{sd})[\mathrm{min}- \\
\max ]\end{array}$ & $\begin{array}{l}\operatorname{mean}(\mathrm{sd})[\min - \\
\max ]\end{array}$ & \\
\hline $\begin{array}{l}\text { Patient Concern } \\
\text { ( } 0 \text { not serene - } 10 \text { quite serene) }\end{array}$ & $\begin{array}{l}6.80(2.94)[0- \\
10] \\
(n=45)\end{array}$ & $\begin{array}{l}4.23(3.12[0-10] \\
(n=43)\end{array}$ & $<0.0001$ \\
\hline $\begin{array}{l}\text { Patient Confidence } \\
\text { (0 Not confident - } 10 \text { very confident) }\end{array}$ & $\begin{array}{l}7.61(2.38)[1- \\
10] \\
(n=38)\end{array}$ & $\begin{array}{l}8.13(2.17)[0-10] \\
(n=39)\end{array}$ & 0.14 \\
\hline Physician attentive to patient & $\begin{array}{l}9.17(1.32)[5- \\
10]\end{array}$ & $9.30(1.13)[4-10]$ & 0.73 \\
\hline \multirow[t]{2}{*}{ Physician attentive to relative } & $\begin{array}{l}9.26(1.22)[5- \\
10]\end{array}$ & $9.30(1.30)[4-10]$ & 0.97 \\
\hline & $\mathrm{n}(\%)$ & $n(\%)$ & \\
\hline Would have liked additional information & $\begin{array}{l}7(16 \%) \\
(n=43)\end{array}$ & $\begin{array}{l}11(26 \%) \\
(n=43)\end{array}$ & \\
\hline $\begin{array}{l}\text { Did not ask all of the desired questions during the } \\
\text { consultation }(n=46)\end{array}$ & $\begin{array}{l}5(11 \%) \\
(n=46)\end{array}$ & $\begin{array}{l}9(19 \%)^{*} \\
(n=47)\end{array}$ & \\
\hline $\begin{array}{l}\text { The doctor thinks the patient/relative } \\
\text { asked all the questions he had to ask }\end{array}$ & $4 / 5$ & $2 / 9 \star *$ & \\
\hline After reflection, they had other questions to ask & $\begin{array}{l}8(19 \%) \\
(n=42)\end{array}$ & $\begin{array}{l}14(32 \%) \\
(n=44)\end{array}$ & \\
\hline
\end{tabular}

*7 relatives because of the patient's presence. ** for the other 7 , the oncologist doesn't know

\section{Figures}




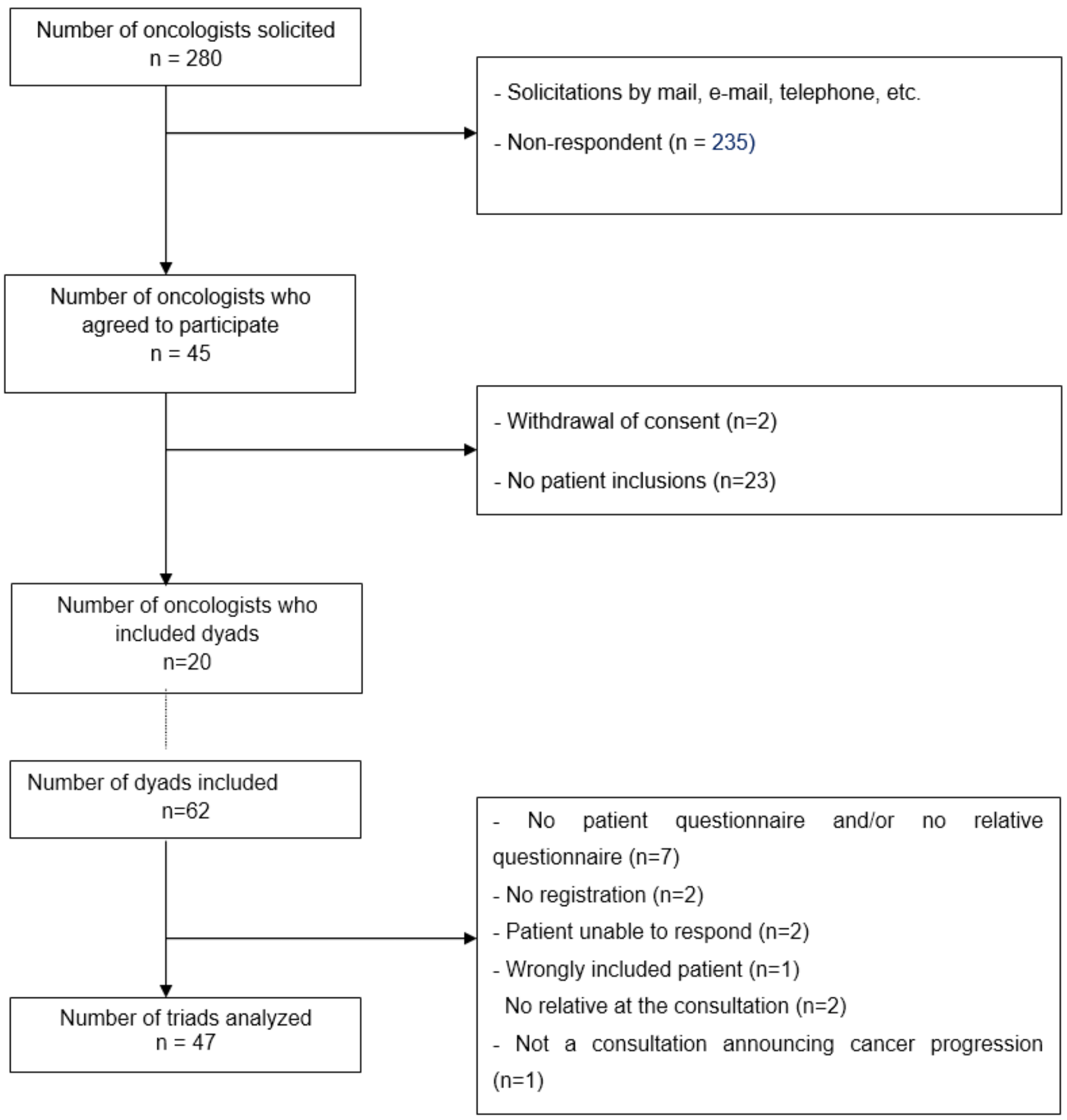

Figure 1

Flow chart

\section{Supplementary Files}

This is a list of supplementary files associated with this preprint. Click to download. 
- Bourgeoispublibabelsupplementarymaterial.docx 